\section{Bnax SciencePrank Research, Organizadion \& Counseling \\ New Trends and Issues Proceedings on Humanities and Social Sciences}

Issue 2 (2017) 47-52

\title{
Experiential psychotherapy methods when working with drug-addict adolescents
}

Andreea Laura Badulescu (Mihaescu) ${ }^{\mathrm{a}} *$, University of Pitesti, Romania Geanina Cucu-Ciuhan ${ }^{\mathrm{b}}$, University of Pitesti, Romania Andra Vasii ${ }^{\mathrm{C}}$, University of Pitesti, Romania

\section{Suggested Citation:}

Badulescu, A.L., Cucu-Ciuhan, G. \& Vasii, A. (2017). Experiential psychotherapy methods when working with drug-addict adolescents. New Trends and Issues Proceedings on Humanities and Social Sciences. [Online]. 02, pp 47-52. Available from: www.prosoc.eu

Selection and peer review under responsibility of Prof. Dr. Marilyn Campbell, Queensland University of Technology, Australia

${ }^{\circledR} 2017$ SciencePark Research, Organization \& Counseling. All rights reserved.

\begin{abstract}
In the middle of age crisis of adolescence, many youngsters find their escape in toxicological substances, giving them the appearances of well being, fear loss, social kills abilities, even an entire other perspective on the reality surrounding them. There are various explanations for these profoundly negative tendencies at adolescents that are going to be discussed in this article. In order to decrease the drug-addiction tendencies, and, at the same time, to stop the maladaptative behaviours and regain the sanity balance, there are urgent needs of psychotherapy interventions, and this case study will discuss the experiential approach when dealing with drug-addictions at adolescents. The experiential psychotherapy is by far one of the most supportive, creative and secured approaches, where the case variables can be shifted like puzzle pieces for reorganise the whole picture on life experiences and identifying the missing pieces that needs to be gain in order to surpass the difficult and emotional consuming life stage, for regaining the sense in terms of personal identity and personal social life. There are some limits of the psychotherapy approach when dealing with a drug-abuse case, that are going to be discussed.
\end{abstract}

Keywords : experiential psychotherapy; case study; drug-addict;

* ADDRESS FOR CORRESPONDENCE: Andreea Laura Badulescu (Mihaescu), University of Pitesti, Romania

E-mail address: psihdr.andreeabadulescu@yahoo.ro Tel.: +403-90198868. 


\section{Hypothesis}

Amid the current socio-existential decline, there can be noticed an evident crisis in an axiological sense, that has a profoundly negative significant impact, in a direct and indirect way, regarding the personal and interpersonal psycho-existential stability.

Therefore, it is highlighted the urgent need of taking-action for the re-balancing of psycho-socioeducational identity, in order to counterbalance the unequal ratio between potentials and abilities, between what you want and what you can, between what is offered and what is received, in a holistic sense.

At a particular level, for the younger generation there is a skidding psycho-behavioral experimentation trend, with direct implications for personal identity and existential destabilization. On the other hand, going on the premises of inter and transgenerational conditioning, victims of disruptive experiences are not only those directly affected but also the collateral ones, which, from an empirical perspective, are waltzing into the vicious circle of roles: rescuer, persecutor, victim.

\section{Objectives}

In the midst of so many unmanageable and hard to reassemble variables, in order to balance the unit, psychotherapy finds its really place and role, participating in its specificity, for shaping an optimum space, supportive and secured, where the involved variables can be shifted like puzzle pieces, able to look at themselves and then identifying the missing halves, so that after a bewildering process, often difficult and emotional consuming, to retrieve and reorganize into a unified image, regaining his sense at an individual and general level.

On situations of substance abuse, the existential situation is becoming more complicated, the therapeutic act can be hindered by the tendency to resignation and disclaimer of personal context, the inability to understand and adapt caused also by the physio-neurological disorders, likely to happen on ongoing substance use, a phenomenon that has its etiological explanation.

The case study presented highly supports the ideological and practical importance of experiential psychotherapy when working with drug-addict youngsters, which proves once again its non-invasive, continuous and balanced therapeutical specific, to rebalance and retrieving individual cognitive and emotional availability, on three stages: awareness, acceptance, redefinition of the trauma and finally, integration, that leads to maturization of the Self.

\section{Methods}

For this case, we used the experiential psychotherapy specific work methods for a drug-addicted subject. Therefore, the projective methods were the main used in our work, meaning: drama therapy work sessions, changing roles,"the empty chair", meditation and relaxation strategies, working with symbols/metaphor.

\section{Study-Case}

Client details (personal life-history)

The client was a 21 years old male, coming from a high socio-economic family level, both parents and an older brother (24 years old). They own a family business that was a successful one until few years ago, now having some financial difficulties that seem to affect all the family, especially the father, who is described as being "very aggressive most of the time, when he is home.. At the work 
place he treats us (the client and the client's brother) as regular employees, no differences what so ever". The mother is described as being "a caring one, but never disobeyed our father, she usually takes good care of us but she never entered in a conflict with him just to protect us". The childhood was "a happy one" as the client says, the family business was at his start and they had everything that they needed (in terms of financial terms). Based on his memories, the father used to drink alcohol at every family meeting, the mother never worked she stayed at home looking for the children. In the big family picture (meaning the relatives too), his family was the center. They were raised based on the principles of "hiding the internal conflicts of the family, from the others - relatives and neighbors)", "no one needs to know what are we doing". Especially for our client, the picture was not so happy because he was often compared by his mother, with his older brother, that was "elder, smarter, more obedient", always given as an example. At school, our client was again compared with his brother, by the teachers. He was "never too good at school. I liked sports but no one in my family was ok with that, so I had to be really good at maths, as my father imposed me, thinking that one day l'll be part of the family business."

Our client describes himself as being a social type, he always had a group of friends but he is convinced now that "'they were my friends because my family was a well-known one and I always had money on me, that I used to share with them. Now I see that, back then I thought that they were really my friends."

Now he is trying to figure out what he likes in terms of professional profile, knowing that he started an economic profile faculty that he abandoned after two years, saying that he couldn't keep up with it, and that there was not even a single person to talk to, amid his colleagues. He felt "left alone".

In terms of social and personal relations, he reminds a few ones, the most significant ones being a relation with an elder girl that his family didn't approve, and another one with a friend's sister, that he felt "obliged" to had, being insistently forwarded to her, by his group of friends and by his mother. He tells that after the break-up with the "biggest love of his life" (the elder female), he accepted to enter in a relation with the girl his mother liked, he didn't "care anymore".

He began consuming during his relationship with the elder female, when she proposed him that during a trip. After the breakup he continued this destructive habit at a high level, based on his low feelings after the separation. He entered a new group of friends that provided him the drugs and he paid for all of his friends, too. After couple of months he began consuming different substances, in high quantities, separating from the family and moving to another house. His mother came daily by his door but always closed, even if he was at home. He told her that he was sleeping most of the time or laying her that he was at school. He used to stay at home with his friends, consuming.

The mother says that she was suspicious regarding her son's behavior, but that she was sure that something is really wrong after she came one day and finds the door open, there was a "specific smell" in the house and "my son's cat was acting really strange, she couldn't walk and making funny sounds. Then I was convinced that my son is on drugs, and I found him lying on the sofa, barely dead. I got really scared, called a relative and begun to search for a place to send my son for recovering."

At the present time he wasn't in any personal relationship, but there were a girl who cared for him during his substance abuse time, named Laura. He didn't felt more but friendly feeling towards her and gratitude for her supportive way.

The mother was the one that required psychological support for his son that was, at that time, recently out of a drug-addict shelter, being on psychiatric medication.

\section{Results}

The unifying experiential therapy it's a holistic psychotherapeutical approach, centered on the symbolistic meaning of psychological content of a person, therefore, a projective method. The 
Badulescu, A.L., Cucu-Ciuhan, G. \& Vasii, A. (2017). Experiential psychotherapy methods when working with drug-addict adolescents. New Trends and Issues Proceedings on Humanities and Social Sciences. [Online]. 02, pp 47-52. Available from: www.prosoc.eu

problem-solving is focusing on provocative exercises, improvisations (role-play) and meditation with creative, expressive and art-therapeutic support.

The client is seen as a whole integrator of all his somatic, psychological and spiritual manifestation. The experiential approach is based on three work sessions: exploring the self, meaning the internal world of the client, analyzing the rapport between the internal world and the external manifestations, the third stage - the externalization (of psychological content), the last but not least, the four stagethe resemnification (the change).

According to experiential theories, the behaviors and cognitive patterns that a person has at some point are the ones that help her to function towards life situations of that period, meaning all that are nothing but coping strategies. The rebalance lays in the capacity of becoming conscious of all maladaptative patterns that keeps the person away from the sanogenetic area.

After the general clinical evaluation, the therapeutic process has started. We worked individually one to one (client-therapist) but also with both son and the mother.

Phase one was to establish the psycho-emotional equilibrium of the client for him to be able to function at a significant level. We focused on "here and now" way of approaching life, to ease the guilty feelings, shame, disappointment and loss of hope. Basically, our client was depressive, the experiential methods were significant for surpassing his estate. We used projective methods all the way of the recovering process. At this stage we used sand play (for reconnecting with his senses, focusing on his current activity, express his emotions in a secure environment).

We tried to find out the internal beliefs and reasons that dominate the client, for better understanding of his actions.

Second, the work aimed to figure out the ways he approaches life, meaning the behavior traits following specific decisions-taking situations. In this stage we have looked

For internal break-ups regarding the perspectives, psychological blockages, coping strategies.

We found that there were several internal conflicts that ruled our client's world: the relation with his father (based on his aggressive trend, lack of positive emotions), the relation with the world (current beliefs that people are false, that they are using him for his money), the school/professional situation (mostly unclear, anxiety producing), the personal love-relationships (most of them unhappy, causing depression).

The client was evoking lots of good memories from that period when "things were all good, I had my friends and lots of fun memories, I used to smile, I had money, no big problems, I had a relation with a loving partner, I played basketball and I did not take drugs. Now, nothing is the same anymore and probably never will. I don't know what to do, I have failed." His first depressive episodes started before taking drugs ant that's a very important thing to underline. We may consider that depression may have a direct implication in drug abuse, leading to a vicious circle that it's very difficult to get out from. Therefore we conducted our therapeutical process focusing on the self (image of the self, selfesteem) to regain the trust in itself and hope towards emotional rebalancing.

At an individual level, we have used the person's drawing, the tree drawing, the nest drawing, all projective methods, to work on his self image, his beliefs, his needs, his fears and resources. All the results were talking about a person strongly affected at an emotional level, with a low emotionalaffective response towards others, unsecured, in need of love and affection. Regarding the person drawing, the lines were very thin, barely seen on the paper, with foot and ears missing, a simple line defining the mouth, the eyes shut. The tree's body was full of vertical lines - that outcomes the passive-aggressive inner self. A big Sun was on this drawing and "the tree is watching it, needing it to grow stronger but seems that the Sun doesn't see him." When drawing the nest, after the person's and the tree's, the client replied "I don't know how to draw, I'm not good at it" (emotional blocking). In the 
end he drew an air-suspended nest (insecure environment), with two eggs (he and his brother) and no bird in or near the nest "the birds are gone; they are looking for food, far away" (the absence of the parents). After finishing all the drawings, he questioned "'" aren't these the most ugly drawings that you have ever seen?" (insecurity, low self esteem, looking for acceptance and validation).

At a family level, we have used the role-play and empty chair methods (drama therapy) for obtaining an image on his relations with his family members. He couldn't play dad's role, he said he just can't be as aggressive as father was, when asked what he would say to his father regarding his needs towards him, he started crying "'I can't speak with him, he's not here" (emotional blockage).

We focused on the image of itself, using imaginary and creative methods like draw what you think you look like - draw what you would like to be focusing on the process from A to B, asking questions like "'What keeps you like this? What you think it might help? How do you think you might get it? What you have to do for it?". The meditation was also involved in the recovering process, to learn how to relax when sober, learning to chill and control his emotions without drugs, to calibrate his positive emotional estate. After a while, he started to practice meditation even at home when he felt anger or disappointment, like a behavioral anchor for inconvenient situations. He learned how important is to have time to reflect before taking any decision or acting impulsively.

Moreover, during the therapeutic meetings, we have had various discussions concerning his life before, in the middle and after consuming, for a better understanding of the reasons and needs that drove him to that maladaptative behavior. He made a list with all the things that made him happy before, like "sports, friends, reading, working at the office, being in love" (as he said), and trying to find at the present time, if he can reconnect with some of the aspects he regrets that he lost (anchors). He started to play basketball again and connect with new people (team colleagues) that shared the same interests. During our sessions, he started to read again, even if at first it was difficult for him to do that because he had difficulty in concentrating and sometimes, in being able to see what he reads. Because we noticed that various times he indicated difficulties in seeing, we have discussed that too. We used the guided meditation for reconnecting with his eyes and visual senses "I have never ever said thank you to my eyes, I have never ever protected them, I haven't even 
C.L. understood that the drugs didn't have such a big control on him as his thoughts and needs had, therefore, being conscious, accepting and being able to resignifying them, could help him to be a better man, having the peace and clarity to change.

The experiential psychotherapy is working with creative, projective and holistic methods, that has a solid positive impact at four different stages that together build the human being, in a holistic sense: the corporal self, the personological self, the adaptative self, the social self.

As the saying goes "a person changes in a good sense when she/he is becoming who he really is, not who he thinks she/he should be".

\section{References}

Mitrofan, I. (2014). Copii si adolescenti. Probleme, tulburari, evaluare si interventie psihoterapeutica (Children and adolescents. Problems, confusions, evaluation and psychotherapeutical intervention). Bucharest, Romania: Alma Mater

Mitrofan, I. (2008). Psihoterapie. Repere teoretice, metodologice și aplicative (Psychotherapy. Theoretical, metodological and aplied guideline). Bucharest, Romania: Alma Mater

Mitrofan, I. (2005). Orientarea experientiala in psihoterapie (Experiential psychotherapy orientation). Bucharest, Romania: Sper 